\title{
Ensinar gênero e sexualidade na escola: desafios para a formação de professores
}

\author{
Lilian Correia Pessôa ${ }^{1}$ \\ Rodnei Pereira ${ }^{2}$ \\ Rodrigo Toledo ${ }^{3}$
}

\section{Resumo}

No último biênio, período em que as discussôes sobre os planos nacional, estaduais e municipais de educação se intensificaram, as questôes sobre gênero estiveram no centro dos debates, tendo sido retiradas da maioria dos planos. Atrelado a isso, há projetos de leis, alguns já aprovados, em âmbito municipal, que intentam coibir que as escolas brasileiras trabalhem com o tema, sob a suposição de "doutrinação ideológica" e de uma tentativa de grupos sociais que lutam pelos direitos das mulheres e da população LGBTT (Lésbicas, Gays, Bissexuais, Transexuais e Transgêneros) de corromper as juventudes. Em uma tentativa de contraposição ao senso comum que vem sustentando essas discussóes, este trabalho problematiza a importância das discussóes de gênero para a formação de professores, a partir do levantamento de dúvidas em um grupo de discussão realizado com jovens de uma escola de ensino médio de ensino integral, na cidade de São Paulo.

Palavras-chave: Gênero e sexualidade. População LGBTT. Formação de professores. Planos de educação.

\begin{abstract}
In the last biennium, when discussions on national, state and municipal education plans intensified, gender issues were at the center of the discussions and were taken from most of the plans. Linked to this, there are draft laws, some of which have already been approved at the municipal level, which seek to prevent brazilian schools from working on the subject, under the assumption of "ideological indoctrination" and an attempt by social groups fighting for women's rights and the LGBTT (Lesbian, Gay, Bisexual, Transsexuals and Transgender) population to corrupt youth. In an attempt to counteract the common sense that has been underpinning these discussions, this paper discusses the importance of gender discussions for teacher training, based on the raising of doubts in a discussion group held with young people from a full-time high school in the city of São Paulo.
\end{abstract}

Keywords: Gender and sexuality. LGBTT population. Teacher training. Education plans.

\footnotetext{
${ }^{1}$ Doutora e Mestre em Educação: Psicologia da Educação pela PUC-SP. Graduada em Pedagogia pela Universidade São Judas Tadeu. Atualmente é Professora no curso de Pedagogia e Coordenadora Local em um dos campi da Universidade Paulista (UNIP). E-mail: < lilipessoa@hotmail.com>.

${ }^{2}$ Doutor e Mestre em Educação: Psicologia da Educação pela PUC-SP. Licenciado em Pedagogia, Filosofia e Letras. Atualmente é Professor no curso de Pedagogia da Universidade Paulista. E-mail: <rodneipereira@uol.com.br>.

${ }^{3}$ Doutorando e Mestre em Educação: Psicologia da Educação pela PUC-SP. Psicólogo e pedagogo, atualmente é Coordenador e Responsável Técnico do Curso de Psicologia da Universidade Ibirapuera, também atua como Supervisor de Estágio e Docente da UNIP nas disciplinas de Psicologia Escolar e Políticas Públicas. E-mail: < toledordg@gmail.com>.
} 


\section{Introdução}

Desde o final do século passado, os movimentos sociais vêm denunciando a exclusão e a violência sofrida por mulheres e pela população LGBTT. É importante destacar o aumento, significativo nos últimos anos, dos índices de crimes motivados por machismo e por homolesbotransfobia ${ }^{4}$ no Brasil.

Contudo, como as discussóes das questốes sobre gênero envolvem, em grande parte, um conjunto de incompreensões sobre a população LGBTT, enfocaremos, neste trabalho, este público.

O Grupo Gay da Bahia (GGB) responsável pela publicação do Relatório Anual de Assassinato de Homossexuais no Brasil (LGBTT) relativo ao ano de 2014, documentou 313 assassinatos de gays, travestis e lésbicas no Brasil. Isso equivale a um assassinato de uma pessoa LGBTT a cada 27 horas.

Essas estatísticas revelam que o conservadorismo - que marca nosso tempo - e o alto índice de intolerância que desembocam em práticas violentas geram impedimentos do reconhecimento do direito à vida.

Acompanhando os dados publicados pelo GGB desde 1999, podemos perceber que a história e a cultura do povo brasileiro - de um modo geral - estão assentadas em uma naturalização de práticas machistas, sexistas e homofóbicas e que vitimam os sujeitos sexuais marginalizados, uma vez que estes têm suas imagens desvalorizadas, o que enseja um clima favorável a violências de todo tipo.

\section{Gênero: uma discussão (des)necessária?}

As violências de gênero, explícitas e veladas, estão nos programas populares de humor, nas "piadas" cotidianas, nas ironias discursivas ordinárias e nos crimes hediondos que voltam à tona, frequentemente, nos noticiários. Se sociedade brasileira não se conscientizar desse contexto de violência, seremos "uma modernidade capenga, injusta, mesquinhamente econômica e economicista", como afirma Souza (2009, p. 12)

Souza (2009) destaca que vivemos em uma sociedade na qual ao invés da oposição clássica entre trabalhadores e burgueses, o nosso "conflito central", tanto social quanto político e que subordina em importância todos os demais, é a oposição entre uma classe excluída - das oportunidades materiais e simbólicas de reconhecimento social - e as demais classes sociais. E é nesse contexto que se instaura a vivência da desigualdade social.

Ao analisar a desigualdade social, Sawaia (2002) propôe uma leitura a partir da dialética inclusão/ exclusão, ressaltando as contradiçôes que constituem o fenômeno da exclusão, pois este contém em si a sua negaçáo, visto que a sociedade exclui para incluir. Esta é a condição indispensável da ordem social desigual, que promove uma compreensão ilusória e perversa de inclusão social.

Diante disso, faz-se necessário questionar o papel do Estado na garantia de direitos fundamentais e direitos sociais. Souza (2009) acrescenta que ao tentarmos isolar o foco de toda atenção na violência espetacular - aquela novelizada, distante e asséptica:

[...] produzimos todas as condiçóes objetivas para a continuação da violência muda e silenciosa de várias dezenas de milhôes de brasileiros, e, no limite, de toda a sociedade brasileira cuja dinâmica é estruturada por uma gigantesca trajetória de desigualdade sociais, econômicas, políticas e culturais (SOUZA, 2009, p. 28).

\footnotetext{
4 "A negação de direitos em razão da orientação sexual e da identidade de gênero recebe o nome de homo-lesbo-transfobia, uma violência que transforma características da diversidade sexual em motivo para desigualdades, vulnerabilidades, exclusões e riscos de toda ordem.” (OIT/ UNAIDS/PNUD, 20I5, p.I7).
} 
Concordamos com o autor quando ele afirma que a violência comumente pode ser entendida como reflexo da reprodução da desigualdade social, que como resultado produz nos sujeitos sofrimento ético-político (SAWAIA, 2002), humilhação social (GONÇALVES, 1998), fatalismo (MARTIN-BARÓ, 1987), alheamento (COSTA, 1997) e desenraizamento (WEIL, 2001).

Especificamente sobre a população LGBTT, cabe mencionar que a Revolução Burguesa na França, no fim do século 18, produziu uma ruptura radical com um passado de criminalização da homossexualidade quando a excluiu da lista de ofensas do seu Código Legal.

Como ressalta Okita (2015), a diminuição da perseguição à população homossexual era o reconhecimento da jovem burguesia democrática aos direitos sexuais burgueses.

Rodrigues (2011) lembra que com a publicação da Declaração dos Direitos dos Homens e dos Cidadãos em 1789, inauguramos um processo histórico de luta pela construção da igualdade, mas a questão central era assegurar os direitos civis elementares e restritos aos homens - exclusivamente do gênero masculino - e proprietários - de determinadas classes sociais - ficando evidente o caráter parcial e restrito dos novos direitos.

É sabido que, historicamente, os negros, as mulheres, os jovens, os indígenas, os trabalhadores e os homossexuais foram e são explorados e oprimidos e estão em luta permanente pelo direito à vida, com um mínimo de dignidade, contra autoritarismos e injustiças de todos os tipos, já que foram populaçóes excluídas desde a gênese do processo de construção da sociedade moderna, da democracia e das proclamaçôes por igualdade e liberdade, como afirma Rodrigues (2011).

Para o autor, a Declaração Universal dos Direitos Humanos de 1948, surge como um marco que busca estabelecer condições mínimas de respeito a cada ser humano, em qualquer tempo e lugar, buscando minimizar todas as perdas das populaçôes subalternizadas historicamente.

$\mathrm{Na}$ década de 1960, reconhecida como um período de ascensão dos movimentos libertários, pacifistas, ambientalistas e de consolidação do movimento feminista, se constituiu um novo sujeito político: aquele que passou a militar no movimento pelos direitos da população LGBTT. Esse movimento teve como paradigma inicial a resistência em Stonewall, nos Estados Unidos, com a reivindicação de igualdade para os que estão fora da norma heterossexista.

Nos estudos sobre o Movimento LGBTT no Brasil, localizamos os primeiros registros de organização entre o final da década de 1970 e o início dos anos de 1980. É sabido que, não somente o Movimento LGBTT, mas outros grupos sociais, nesta época, articulavam-se pela defesa da visibilidade, pela construção de novas formas de conhecimento, de cidadania e pela luta por direitos civis, conforme afirma Ferrari (2004).

Para o autor, as reivindicaçóes dos movimentos sociais - em especial do Movimento LGBTT - demonstravam a importância do contexto político em que se desenvolviam, pois o fim da ditadura militar produziu uma espécie de "otimismo" social.

Com a abertura política, tornava-se novamente possível pensar na construção de uma sociedade mais democrática, igualitária e justa, como afirma Ferrari (2004). Havia esperança para o Movimento LGBTT de formar uma sociedade em que a sexualidade poderia ser vivida sem restrições, mas não tem sido táo fácil o reconhecimento dos direitos civis da populaçáo LGBTT. 
Rodrigues (2011) explica que mesmo antes da abertura política vivida nos anos 1980, os movimentos de esquerda, socialistas e de trabalhadores, tiveram dificuldade em incorporar os grupos que reivindicavam espaço para a discussão dos direitos das mulheres, o combate ao racismo e, especialmente, os direitos sexuais.

Rodrigues (2011) e Ferrari (2004) afirmam que, para alguns movimentos sociais, durante muito tempo, a questão da igualdade entre homens e mulheres, a equidade entre negros e não-negros e o reconhecimento da diversidade sexual sempre se apresentaram como questão menor ou simplesmente como uma não-questão, mesmo em movimentos reconhecidamente progressistas.

Rodrigues (2011) pondera que, de certa maneira, a discussão sobre os direitos sexuais já estava incorporada desde a Revolução Francesa que tinha como um dos seus pressupostos o reconhecimento de que todos são iguais perante a lei. Portanto, para ele, reconhecer os direitos civis dessa população, seria o primeiro passo para o reconhecimento de direitos. Se todos são iguais perante a lei, ao Estado náo seria admissível tratar os cidadãos de maneira diferente, com isso, deveria estar claro que ninguém poderia ser discriminado ou deixar de usufruir algum direito em virtude do seu gênero, etnia, orientação sexual ou pela sua identidade de gênero.

Desde sua constituição, em 1945, a Organização das Naçóes Unidas - ONU, nunca havia se manifestado ou tratado sobre as temáticas que envolvessem o debate sobre sexualidade e direitos sexuais, até que, na década de 1980, reportou a pandemia de HIV/Aids, relacionando-a com a homossexualidade, como afirma Gorisch (2014).

Para Daniel e Parker (1991), diante do posicionamento da ONU e com o advento da Aids, no início dos anos 80 , acirraram-se os preconceitos contra a população LGBTT, destacando os homens homossexuais, e a própria condição de homossexualidade masculina era associada ao HIV.

Os autores destacam que essa associação era tão forte que a doença chegou a ser chamada de GRID (Gay Related Immunedeficiency), nos meios científicos, e de câncer gay, peste gay ou peste rosa pela imprensa e pela população em geral.

Durante o agravamento da epidemia de Aids, acompanhamos o esvaziamento e o encerramento das atividades de vários grupos importantes para a organização e consolidação do movimento LGBTT no Brasil, como o grupo Somos de São Paulo e o jornal Lampião da Esquina, um dos principais meios de comunicação para o movimento.

MacRae (1990) afirma que o novo contexto de democracia do país exigia uma mudança de perfil para a continuidade dos grupos, pois com o fim da ditadura, acenava uma possível abertura de canais de comunicação com o Estado, embora, em relação ao movimento homossexual, estes canais só tenham surgido quando se compreendeu que a epidemia do HIV era um problema de saúde pública e não apenas de "grupos de risco".

Ainda durante os anos de 1980, foi possível observar o deslocamento dos grupos e movimentos LGBTT para outras regiôes do país, além do eixo Rio de Janeiro-São Paulo. Dentre estes podemos citar o GGB - Grupo Gay da Bahia.

Para Facchini e França (2009) os novos grupos e organizaçóes do movimento LGBTT, demonstravam uma ação mais pragmática, voltada para a garantia dos direitos civis e contra a discriminaçáo e a violência dirigidas à populaçáo LGBTT. Nesse período, foram obtidas grandes conquistas, como a retirada da homossexualidade do código de doenças do Instituto Nacional de Previdência Social, a adoção e a disseminação 
da ideia de orientação sexual em detrimento da lógica de opção sexual, assim como um intenso debate acerca da inclusão da garantia de não-discriminação por orientação sexual na Constituição Federal de 1988.

A partir da década de 1990, como destacam Facchini e França (2009), o movimento se multiplicou e, com ele, as categorias de referência ao seu sujeito político. Assim, em 1993, ele apareceu descrito como MGL (Movimento de Gays e Lésbicas) e, após 1995, surgiu primeiramente como um movimento GLT (Gays, Lésbicas e Travestis) e, posteriormente, a partir de 1999, começou a figurar também como um movimento GLBT (Gays, Lésbicas, Bissexuais e Transgêneros), passando pelas variantes GLTB ou LGBT, a partir de hierarquizaçóes e estratégias de visibilização de cada segmento.

No XII Encontro Brasileiro de Gays, Lésbicas e Transgêneros de 2005, foi aprovado o uso de GLBT, incluindo oficialmente o $\mathrm{B}$ de bissexuais à sigla aceita no país e convencionando que o $\mathrm{T}$ se refere a travestis, transexuais e transgêneros. A solução provisória encontrada pelo XII EBGLT foi posteriormente revogada e, em 2008, o evento já se chamava EBLGBT (Encontro Brasileiro de Lésbicas, Gays, Bissexuais, Travestis e Transexuais). A sigla do EBLGBT acompanhou a mudança ocorrida em meados do ano de 2008, a partir da Conferência Nacional GLBT, quando foi aprovado o uso da sigla LGBT para a denominação do movimento, o que se justificaria pela proposta de visibilizar o segmento das lésbicas (FACCHINI; FRANÇA, 2009, p. 62-63).

Dessa maneira, percebemos a falta de concordância e de contradiçóes existentes no movimento LGBTT, pois as siglas que procuram definir o sujeito político do movimento é apresentada de múltiplas maneiras.

Todas estas articulaçôes para a definição dos sujeitos políticos do movimento LGBTT, nos permitem compreender as transformaçóes ocorridas na transição dos anos de 1980 para os anos 1990, como destacam Facchini e França (2009).

A partir do início dos anos 1990, pode se dizer que o número de grupos/ organizações do movimento voltou a crescer, espalhando-se por todo o país, ao mesmo tempo em que seus formatos institucionais e suas propostas de atuaçáo diversificavam-se. Por outro lado, nota-se também uma ampliaçáo da rede de relaçóes sociais do movimento e a presença de novos atores nesse campo, por exemplo, a mídia, as agências estatais ligadas aos temas justiça e saúde, parlamentares que incluem a bandeira dos direitos dos homossexuais em suas plataformas, o mercado especializado, organizaçōes internacionais e grupos religiosos flexíveis ou especialmente voltados a questóes ligadas à sexualidade (FACCHINI, 2005, p. 61).

Para as autoras, um exemplo da diversificação de formatos institucionais e da transformação das relaçóes estabelecidas pelo movimento com outros atores diz respeito à relação entre o movimento LGBTT e partidos políticos. Nos anos 1990, assistimos à organização de setoriais LGBT em partidos como o PT (Partido dos Trabalhadores) e o PSTU (Partido Socialista dos Trabalhadores Unificados), bem como o lançamento de candidaturas e a proposiçấo de projetos de lei, o que demonstravam uma transformação nas relaçóes entre militantes do movimento LGBTT e partidos políticos.

Podemos destacar que desde os anos 1990 tem-se ampliado o número de partidos que têm se aproximado da temática LGBT e também tem crescido a constituiçấo de setoriais, de açóes de parlamentares e de candidaturas que se organizam a partir de uma identificação - explícita - como o movimento LGBT.

Ainda durante os anos 1990 podemos destacar diversas conquistas para o movimento, como a proposição do projeto de lei sobre a parceria civil entre pessoas do mesmo sexo, em 1995. Esta proposição foi um 
marco que indicou as primeiras conquistas dessa articulação LGBT pela via partidária. Temos também os avanços propostos pela LDB - Lei de Diretrizes e Bases para a Educação de 1996 e pelos PCNs - Parâmetros Curriculares Nacionais, de 1997.

No entanto, as primeiras demonstrações mais vivas de reconhecimento de LGBT nas políticas públicas e nos programas de governo apareceram de modo mais expressivo apenas nos anos 2000.

Açóes que visavam propor o enfrentamento ao sexismo e à homofobia encontram suporte em proposł tas como no Programa Nacional de Direitos Humanos II (de 2002), no Plano Nacional de Políticas para as Mulheres (2004), no Programa Brasil sem Homofobia (2004) e no Plano Nacional de Educação em Direitos Humanos (2006).

Torna-se necessário destacar o Programa Brasil sem Homofobia (2004) que teve como principal objetivo discutir práticas para o combate à violência e ao preconceito contra a população LGBTT (Lésbicas, Gays, Bissexuais, Travestis e Transexuais), nos diversos âmbitos das políticas públicas.

Evidenciando o crescente número de violência contra a população LGBTT, o MEC - Ministério da Educação, compreende que seria necessário discutir as temáticas de gênero e sexualidade na formação - inicial e continuada - de profissionais da educaçáo e com isso nasceu o Projeto Escola sem Homofobia (2004), ou ainda, o "kit gay" como foi pejorativamente conhecido pela população.

O material que compunha o Projeto Escola sem Homofobia tinha como objetivo contribuir para a implementação e a efetivação de ações que promovam ambientes políticos e sociais favoráveis à garantia dos direitos humanos e da respeitabilidade das orientaçôes sexuais e identidade de gênero no âmbito escolar brasileiro. $\mathrm{E}$ como é de conhecimento público, quando estava pronto para ser impresso e distribuído, setores conservadores da sociedade e do Congresso Nacional tencionaram o Governo Federal e o projeto foi engavetado.

Nos últimos anos, temos acompanhado diversas discussóes que envolvem direta ou indiretamente a população LGBTT, como projetos de lei que reconhecem o casamento, autorizam a adoção de crianças por casais homoafetivos, realização de cirurgias e distribuição de hormônios para transexuais, criminalização da homofobia, estatuto da família, despatologização de identidades trans, entre várias outras discussóes. Mas dentre todos estes debates, o que mobilizou intensamente os movimentos sociais e o debate público foram as discussōes em torno do PNE - Plano Nacional de Educação de 2014 e dos PMEs - Planos Municipais de Educação, de 2015.

Mesmo com a pressão dos movimentos LGBTT, o PNE de 2014 definiu entre suas diretrizes a superação das desigualdades educacionais, com ênfase na promoção da cidadania e na erradicação de todas as formas de discriminação e a promoção dos princípios do respeito aos direitos humanos, à diversidade e à sustentabilidade socioambiental. No texto aprovado foi retirada qualquer menção às temáticas diretamente ligadas ao campo do gênero e da sexualidade.

O debate se tornou mais intenso e com forte mobilizaçáo de diversos setores da sociedade, no momento das discussões sobre os PME. As articulações municipais tentaram - fortemente - combater as críticas conservadoras, mas o número de prefeituras que aprovou seus Planos Municipais de Educação comprometendo-se com o debate de gênero e sexualidades foi muito pequeno. 
Trabalhos como os de Lins, Machado e Escoura, 2015; Miskolci e Junior, 2014; Rodrigues, 2011 e Okita, 2015, indicam que há uma oposição forte da população conservadora às pessoas LGBTT. Essa oposição tem contribuído com a violação de direitos e, por isso, os avanços na agenda LGBTT têm se mostrado difíceis, pois fica claro que há uma força contrária que impede o reconhecimento dos direitos das minorias sexuais. Um exemplo claro disso são os discursos do deputado federal Jair Bolsonaro, que explicitamente faz discursos de ódio contra as pessoas LGBTT, como noticiam amplamente os meios de comunicação de massa.

Além disso, ainda que o Brasil seja um dos sessenta e seis países signatários da Carta de Princípios de Yogiakarta de 2007 - documento que tem como fundamento a aplicação da legislação internacional de Direitos Humanos em relação à orientação sexual e identidade de gênero -, o país ainda não conseguiu superar a sua estrutura de opressão e submissão da população LGBTT.

O comportamento homossexual continuou ameaçando o funcionamento da família patriarcal de tal maneira que teve que ser regulado, perseguido e, em alguns casos, eliminado. É preocupante perceber que ainda existem movimentos de perseguição e extermínio - principalmente de mulheres, LGBTT e negros - se repetindo em larga escala, nos últimos anos.

Como afirma Santos (2014) a vivência e o acesso diferenciado a recursos, tanto de ordem material como simbólica, caracteriza o cenário no qual vivemos e construímos nossas subjetividades.

Motivados por esses aportes teóricos, nos dispomos a investigar as concepçóes e as dúvidas sobre gênero, de um grupo de estudantes de uma escola de ensino médio, de tempo integral.

\section{Metodologia}

Com o objetivo de analisar as concepções e dúvidas dos participantes, optou-se pela abordagem qualitativa de pesquisa que, segundo André (2013, p. 97), tem como foco de atenção "[...] o mundo dos sujeitos, os significados que atribuem às suas experiências cotidianas, sua linguagem, suas produções culturais e suas formas de interações sociais".

Para coleta dos dados desenvolveu-se um grupo de discussão (WELLER, 2006) com 10 jovens, entre 15 e 17 anos, que estudavam em uma escola de ensino médio de ensino integral, no segundo semestre de 2016, localizada na zona leste da cidade de São Paulo, a partir de 3 proposiçóes, quais sejam: Há espaço para se discutir gênero na sua escola? Vocês consideram importante discutir esse tema? Vocês consideram que essa discussão traria prejuízos ou seria importante para a sua formação? Por quê?

A discussão durou cerca de uma hora e buscou compreender as visóes do grupo sobre o tema, sobretudo em relação às experiências, posiçôes e interpretações comuns. A conversa foi gravada e transcrita, gerando os dados que foram tratados e analisados.

\section{Resultado e Análise}

A análise dos dados buscou inspiração na análise de prosa (ANDRÉ, 1983), contemplando os seguintes movimentos: 
Figura 1 - Procedimentos de organização de dados, a partir da Análise de Prosa

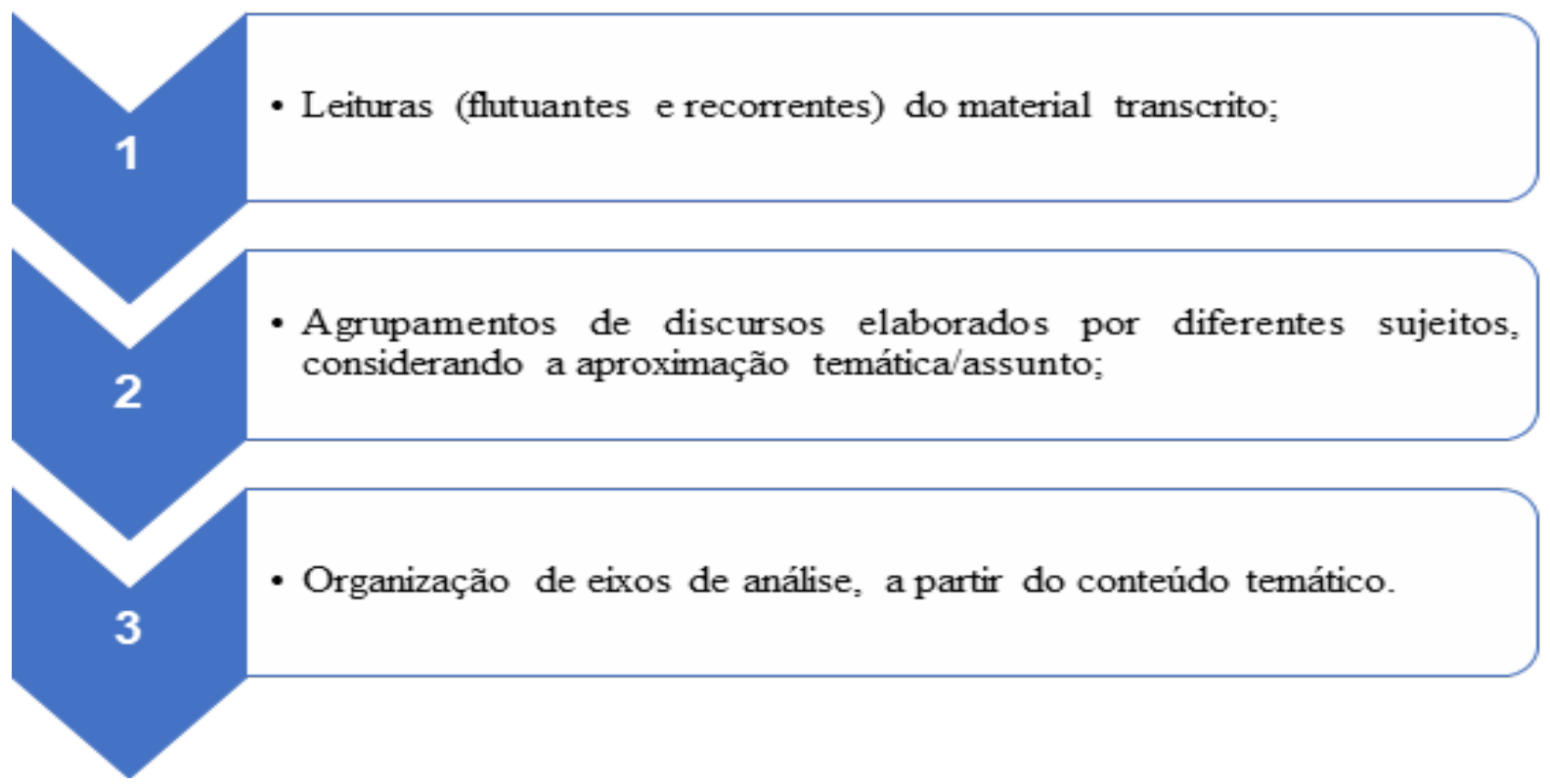

Fonte: Elaboração dos autores, a partir de André (1983, p. 67-68)

Esse processo permitiu a criação de 2 grandes temas, organizados após a análise do conteúdo das transcriçóes, segundo os movimentos indicados acima:

\section{Figura 2 - Eixos de análise gerados a partir do grupo de discussão}

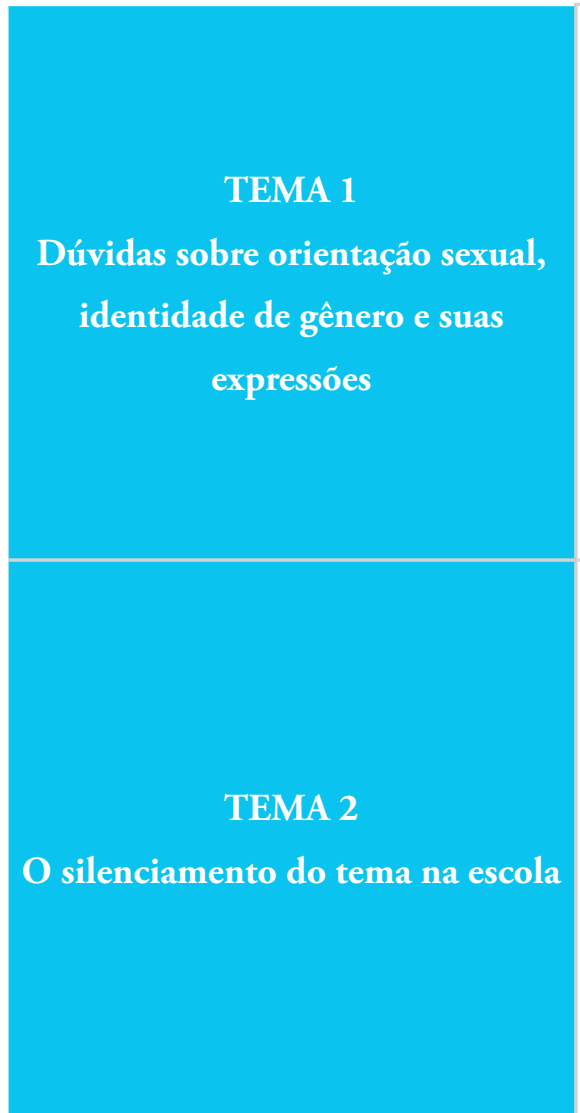

"Uma pessoa nasce transexual?".

"Uma pessoa bissexual é indecisa?".

"A pessoa nasce gay?".

"O que faz uma pessoa virar gay?”.

"Se um casal gay tiver um filho, isso pode influenciar [ela] a ser gay também?”.

"Que banheiro travestis e transexuais devem usar?".

"A escola não fala desse assunto. Se tivesse mais momentos como esses, acho que ia ser muito bom. Pra gente entender...”.

"[...] outro dia perguntei pra professora e ela disse que isso não tinha nada a ver com o assunto da aula e que náo interessava”. "Fico pensando que a escola poderia ajudar as pessoas a sofrerem menos. Por exemplo, como fazer para uma familia muito religiosa aceitar seu filho?". "Aqui na escola, tem gente, assim, de todo tipo. Por que no resto do mundo não pode ser assim?”.

Fonte: Elaboração dos autores. 
Por sua vez, cada um dos temas foi discutido no eixo de análise "gênero, sexualidade e educação na formação de professores". Nele, procurou-se problematizar os desafios que os conteúdos levantados nas discussōes com os jovens podem trazer para a formação de professores, de modo que optamos por não discutir o conteúdo e os significados das falas e concepçôes dos jovens em si, neste trabalho.

\section{Discussão dos dados: gênero, sexualidade e educação na formação de professores}

A formação continuada de professores até então praticada no contexto escolar, em geral, pauta-se numa perspectiva de "ensinar aos professores o que deve ser repassado aos alunos". Essa lógica remete-nos à formaçáo como um modo de preencher "lacunas" deixadas na formação inicial do professor, isto é, oferecer ao professor uma forma de compensação dos conteúdos que supostamente lhe fazem falta na atuação docente e dos quais ele foi privado na formação inicial. Nessa perspectiva, Silva (2003, p. 122), revela que

Os professores assumem-se mais como espectadores do que como autores do seu processo de formação. [...] preferindo ser consumidores de formação a autores da mesma, acabando por alimentar um sistema de que são eminentemente críticos, mas do qual se tornam conscientemente cúmplices, pelo jeito que lhes dá.

O posicionamento do autor nos chama a atenção para fato de que, apesar de criticarmos as perspectivas tradicionais de ensino, especialmente por desconsiderarem a bagagem experiencial dos alunos, representada pela famosa metáfora da tábula rasa, quando organizamos ações de formação é justamente a esse modelo que recorremos. Alimentamos, portanto, ainda que não percebamos, um sistema de ensino (o tradicional) do qual somos eminentemente críticos, mas na falta de conhecimento ou afinidade com uma proposta melhor, o perpetuamos. $\mathrm{Ou}$, ainda, nas palavras do autor, dele nos tornamos conscientemente cúmplices.

Ainda, referindo-nos às deficiências contidas nos modelos atuais de formação, encontramos outro aspecto ao qual não se pode deixar de fazer referência: trata-se do efeito "telefone sem fio"s que costuma ocorrer em tais modelos. Esse efeito acontece na medida em que conteúdos são repassados aos professores para que estes os repassem aos alunos, já que em tais repasses ocorrem distorçôes e distanciamentos da proposta concebida originalmente (proposta esta que já pode carregar em si o grande potencial de não ser a mais adequada, se não foi concebida pelos profissionais do contexto em que será desenvolvida, tal como geralmente acontece).

Se concordamos que a escola precisa ser um local em que o debate sobre gênero e sexualidade, entre outros assuntos, tenha espaço garantido e possa vir à tona com toda a expressão que merece, concordamos também que a formação deve ser repensada, pois não pode mais ser concebida considerando-se uma lógica pouco produtiva em que um ensina e o outro aprende.

As vozes dos alunos do ensino médio expressas no Tema 2 (Silenciamento do tema na escola), revelam as consequências dessa formação inconsistente. Assistimos a adoção de uma série de procedimentos indesejáveis por parte dos professores, denunciando uma atuação profissional com pouca ou nenhuma au-

\footnotetext{
${ }^{5}$ Referência feita à brincadeira infantil, intitulada "Telefone sem fio", que consiste em organizar um grupo de pessoas uma ao lado da outra, sendo que o primeiro irá dizer uma frase, pronunciando-a baixinho, tão próximo quanto possível do ouvido de quem estiver ao lado. Por sua vez, esta pessoa imediatamente fará o mesmo até chegar na última pessoa que deve pronunciar a frase em voz alta. Normalmente, o resultado é a pronúncia de uma frase muito diferente daquela que foi dita ao primeiro participante da brincadeira, o que garante a diversão de todos.
} 
tonomia, sem compromisso com a formação integral do aluno nem com o desenvolvimento do seu pensamento crítico e reflexivo, sem qualquer preocupação com as questôes relacionadas a gênero e sexualidade. As atividades propostas são desprovidas de sentido (tanto na perspectiva do aluno como na perspectiva do próprio professor) e algumas estratégias adotadas na tentativa de dinamizar a aula e resgatar o interesse do aluno pelo aprender fracassam, pois têm como princípio "o lúdico pelo lúdico, a dinâmica pela dinâmica" dada a falta de propósito didático, de direção pedagógica, de consciência sobre o que é necessário para o desenvolvimento do aluno.

Uma das hipóteses que justificam essa ausência de envolvimento dos professores com a proposta de formação, refere-se ao fato de que eles foram deixados de lado no momento de tomar decisóes sobre os rumos da formação e, portanto, não criam vínculos de identidade ou de pertença que os mobilizem para atuar em prol do sucesso da proposta. Ao tratar dos danos que podem advir da falta de envolvimento dos professores no trabalho de formação, Pessôa $(2015,44)$ alerta que:

Assumir uma posição de espectador é destituir-se de toda a responsabilidade com o processo, visto que não há implicação ou compromisso assumidos. Esta é uma consequência desastrosa quando se defende uma atuação profissional com base em princípios de autonomia, por exemplo. Ao colocar-se na posição de quem "assiste" a formação, o fracasso ou o sucesso do que será feito a partir de então não dependerá mais de uma atuação profissional consistente, mas do fator 'sorte', talvez por haver semelhança entre os contextos (o da formação e o da ação) quando, então, a formação poderá ter alguma validade.

As escolas não têm criado momentos de diálogo, debate e acolhida às dúvidas e dificuldades enfrentadas cotidianamente pelo professor. Se o professor não é ouvido no momento em que a sua formação é concebida, como esperar que essa mesma formação venha a ter para ele algum sentido? Consequentemente, se ele não é ouvido, como esperar que ouça o seu aluno quando este se inquieta com dúvidas, tais como as apresentadas no Tema 1 (Dúvidas sobre orientação sexual, identidade de gênero e suas expressóes)? Como ignorar o quão difícil tem sido para os professores trabalharem com a temática "diversidade de gênero e educação sexual" na escola? Será que os formadores de professores sabem como fazê-lo? Como romper com esse ciclo que fecha os olhos para assuntos de elevada importância, por não saber como lidar, como abordá-lo, como obter o apoio da família, onde buscar informaçóes e como acolher diferentes posicionamentos que possam surgir?

Especialmente quando nos referimos às dúvidas e aos comentários feitos pelos alunos do ensino médio, citados neste estudo, notamos o quanto aquilo que dizem denuncia a falta de informação e a ausência da abordagem sobre a temática relacionada a gênero na escola. Quando um aluno diz: "A escola não fala desse assunto. Se tivesse mais momentos como esses, acho que ia ser muito bom. Pra gente entender [...]", expóe toda a sua expectativa em relaçáo às dúvidas que possui sobre gênero e sexualidade, mas, ao mesmo tempo, expressa sua frustração por não encontrar na escola o espaço para o diálogo de que necessita.

Suas dúvidas, medos e anseios em relação a questôes sobre gênero e sexualidade não são atendidos, já que a temática costuma ser silenciada nas escolas, num consenso velado entre os profissionais que nela atu- 
am, quais sejam: professores, coordenadores e diretores, supervisores. Parece haver um acordo tácito em que todos concordam que o melhor a fazer é ignorar o assunto, desviar a atençâo para outros conteúdos, evitar a "polêmica" advinda do tema, calar-se diante de ideias pré-concebidas ou de concepções distorcidas.

Entretanto, se não queremos olhar para a formação de professores numa lógica escolar, ou seja, se não queremos colocar o professor no papel de aluno, mas queremos, isto sim, favorecer o seu desenvolvimento profissional, entendido como o desenvolvimento que inclui:

[...] quer a aprendizagem eminentemente pessoal, sem qualquer tipo de orientação, a partir da experiência (através da qual a maioria dos professores aprendem a sobreviver, a desenvolver competências e a crescer profissionalmente nas salas de aula e nas escolas), quer as oportunidades informais de desenvolvimento profissional vividas na escola, quer ainda as mais formais oportunidades de actividades de treino e de formação contínua, interna e externamente organizadas (DAY, 2001, p.18).

Promover o desenvolvimento profissional dos professores para que eles possam atuar em prol do desenvolvimento integral dos seus alunos implica, portanto, considerar o professor como sujeito do processo formativo, incluindo sua bagagem pessoal e profissional. Já não nos é possível negar a importância dessas duas dimensões na atuação docente, especialmente quando nos foram reveladas, por jovens do ensino médio, questionamentos que se chocam com valores pessoais (dimensão pessoal) diferentes dos seus e que, portanto, não saberão como lidar (dimensão profissional).

Talvez o maior desafio que enfrenta o professor quando lida com questóes que se referem a gênero e sexualidade, seja justamente a necessidade de romper com os seus próprios paradigmas, de se colocar num processo contínuo de desconstruçáo e reconstruçáo de valores socialmente construídos (muitos dos quais historicamente superados, modificados e sem sentido). A primeira questão sobre gênero e sexualidade com a qual o professor precisa lidar na escola refere-se ao conflito que pode haver entre o seu papel como o profissional que deve garantir o respeito e a compreensão relativos à diversidade de valores, crenças, condiçóes e escolhas de outrem e as suas escolhas pessoais, que não devem ser apregoadas a ninguém, mas aceitas e respeitadas como as de qualquer outra pessoa. Para ser professor e enfrentar os desafios da educação atual, será preciso enfrentar-se a si mesmo.

Outro enfrentamento igualmente necessário, e talvez táo dolorido para o professor quanto o anterior, é lidar com a família dos alunos. Se lidar com os próprios sentimentos, valores, crenças e emoçôes já é uma tarefa suficientemente complexa, lidar com toda essa gama de constructos sociais das famílias é problema exponencialmente maior. Os pais e a comunidade ditam as regras "morais" que acreditam que a escola deve seguir e ratificar na educaçáo dos seus filhos. E o professor, que mal tem argumentos para convencer-se a si mesmo, sente-se derrotado e impotente no primeiro questionamento feito pela família que vai à escola discordar da sua proposta de discutir o tema gênero e sexualidade com a clareza que o assunto requer.

Essas razôes já são suficientes para que muitos professores prefiram não lidar com a temática. Ignorá-la na escola, como revela o depoimento de um dos jovens do ensino médio "[...] outro dia perguntei pra professora e ela disse que isso não tinha nada a ver com o assunto da aula e que não interessava"; adiá-la tanto quanto for 
possível; tratá-la de modo superficial (só pra poder aliviar um pouco a culpa); dentre outras formas de fuga, têm sido estratégias utilizadas com algum sucesso pelos professores. Entretanto, é evidente, que isso não tem efeito na formação do aluno e urge que se lance um olhar mais cuidadoso em relação à formação do professor para que essa condição possa ser modificada.

É preciso viabilizar discussōes e reflexões que permitam a esse profissional rever sua atuação profissional, sem prejuízo de suas escolhas e crenças pessoais ou de seus alunos, quaisquer que sejam elas, pois o princípio que deve imperar no processo educativo é o do esclarecimento, do debate, da reflexão mas, acima de tudo, do respeito à escolha, à crença e à condição do outro.

Para tanto, não se pode suprimir ou menosprezar a dimensão pessoal e emocional da atuação profissional do professor. Ela ocupa um papel de fundamental importância nesse processo. É como alerta Day (2001, p.219) que:

Todos os professores têm necessidades de desenvolvimento que se prendem, por um lado, com a relação entre a idade, a experiência, o saber-fazer e o empenho e, por outro, com a sua capacidade contínua de aplicar a inteligência emocional em situaçóes de ensino e em culturas escolares que exigem o uso de juízos discricionários e de tacto pedagógico. Neste contexto, quando se pretende planear a formação contínua é fundamental analisar o modo como ela contribui para o desenvolvimento de tais capacidades.

\section{Considerações finais}

Como se pode verificar, as discussôes sobre gênero e sexualidade são temáticas importantes e urgentes, já que estâo relacionadas à preservação da vida e aos direitos humanos. Os jovens, como sujeitos em formação têm dúvidas e necessidades formativas que deveriam ter acolhidas e trabalhadas na/pela escola, que assumiu a função social de transmitir os conhecimentos acumulados pela humanidade ao longo dos tempos, especialmente no que diz respeito ao avanço da ciência e das tecnologias. Para tanto é preciso lembrar que isso é direito dos estudantes, já que um dos objetivos declarados pela escola brasileira é educar para a cidadania.

Contudo, os professores não podem ser culpabilizados por não terem condiçôes objetivas de entrarem em contato com os elementos que poderiam impulsionar seu desenvolvimento profissional - dentre eles receber formação -, de modo que se sentissem capazes e eticamente comprometidos com temas complexos como gênero e sexualidade.

A omissão do Estado em instituir políticas educacionais que tomem as discussões de gênero e sexualidade com a seriedade e o rigor que merecem só acirra desigualdades e violências. E neste caso, cabe-nos, como profissionais da pesquisa e do ensino, denunciar os resultados de tal omissão e pressionar o poder público quanto à implementação de políticas públicas que estão "aprisionadas" no âmbito do poder legislativo, para que professores e alunos tenham acesso aos conhecimentos e aportes necessários para o seu pleno desenvolvimento pessoal e profissional. 


\section{Referências}

ANDRÉ, M. E. D. A. Texto, contexto e significados: algumas questões na análise de dados qualitativos. Disponível em: <http://publicacoes.fcc.org.br/ojs/index.php/cp/article/view/1491/1485>. Acesso em: 02 dez. 2016.

COSTA, J. F. O alheamento. In: COSTA, J. F. (org.). A ética e o espelho da cultura. Rio de Janeiro: Rocco, 1994.

DANIEL, Herbert; PARKER, Richard. AIDS: a terceira epidemia. São Paulo: Iglu Editora, 1991.

DAY, Christopher. Desenvolvimento Profissional de Professores: os desafios da aprendizagem permanente. Porto: Porto Editora, 2001.

ESCOREL, Sarah. Exclusão social fenômeno totalitário na democracia brasileira. Saúde soc., São Paulo, v. 2, n. 1, p. 41-57, 1993. Disponível em: <http://www.scielo.br/scielo.php?script=sci_arttext\&pid=S0104-12901993000100005\&lng=en\&nrm=iso >. Acesso em: 06 set. 2016.

FACCHINI, R. Entre compassos e descompassos: um olhar para o "campo" e para a "arena" do movimento LGBT brasileiro. Bagoas: revista de estudos gays: gênero e sexualidades. EDUFRN, Natal, v. 3, n. 4, jan./jul.2009. Disponível em: <https://periodicos.ufrn.br/bagoas/article/view/2300>. Acesso em: 06 set. 2016.

FACCHINI, R. Sopa de letrinhas? Movimento homossexual e produção de identidades coletivas nos anos 90. Rio de Janeiro: Garamond, 2005.

FACCHINI, R.; FRANÇA, I. L. De cores e matizes: sujeitos, conexóes e desafios no Movimento LGBT brasileiro Sexualidad, Salud y Sociedad - Revista Latinoamericana, núm. 3, 2009, pp. 54-81. Disponível a partir <http://www.e-publicacoes.uerj.br/index.php/SexualidadSaludySociedad/article/view/41/468>. Acesso em: 06 set. 2016.

FERRARI, A. Sujeitos, subjetividades e educaçáo. Juiz de Fora: Editora UFJF, 2010.

FERRARI, A. Você já deve saber da minha "orientaçáo sexual” (se não sabia, ficou sabendo agora, hehe!) - subjetividades e sujeitos em negociação. In: FERRARI, A. Sujeitos, subjetividades e educaçáo. Juiz de Fora: Editora UFJF, 2010.

FOUCAULT, Michael. História da sexualidade: vontade de saber. Rio de Janeiro: Edições Graal, 1988.

GATTI, B. A; BARRETTO, E. S. de S.; ANDRÉ, M. E. D. A. Políticas Docentes no Brasil: um Estado da Arte. Brasília, Unesco, 2011.

GONÇALVES, M. G. M. Fundamentos metodológicos da psicologia sócio-histórica. In: BOCK, A.M.B.; GONÇALVES, M. G. M.; FURTADO, O. (orgs.). Psicologia sócio-histórica - uma perspectiva crítica em psicologia. 3 ed. São Paulo: Cortez, 2007, pp. 139-153.

GONÇAlVES, M. G. M. Psicologia, Subjetividade e Política Públicas. São Paulo: Cortez, 2010. 
GONÇALVES, M. G. M.; e BOCK, A. M. B. A dimensão subjetiva dos fenômenos sociais. In:

BOCK, A.M.B.; GONÇALVES, M.G.M. (Orgs.). A Dimensáo Subjetiva da Realidade: uma leitura sócio-histórica. São Paulo, Ed. Cortez, 2009, p.116-157.

LINS, B. A.; MACHADO, B. F.; ESCOURA, M. Diferentes, não desiguais: a questão de gênero na escola. Sáo Paulo: Editora Reviravolta, 2016.

MARTIN-BARÓ, I. Para uma psicologia da libertação. In: GUZZO, R. S. L.; LACERDA JUNIOR, F. (orgs.), Psicologia Social para América Latina: O resgate da Psicologia da Libertação. Campinas: Alínea, 2011.

MARTIN-BARÓ, I. O papel do Psicólogo. Estud. psicol. (Natal), Natal, v. 2, n. 1, p. 7-27, junho de 1997. Disponível em: <http://www.scielo.br/scielo.php?script=sci_arttext\&pid=S1413-294X1997000100002\&lng=en\&nrm=iso>. Acesso em: 06 set. 2016.

McRAE, Edward. A construçáo da igualdade: identidade sexual e política no Brasil da "Abertura". Campinas: Editora da Unicamp, 1990.

MISKOLCI, R.; LEITE JUNIOR, J. (org.). Diferença na educação: outros aprendizados. São Carlos: EdUFSCar, 2014.

OIT/UNAIDS/PNUD. Promoçáo dos Direitos Humanos de pessoas LGBT no Mundo do Trabalho. 2. ed. Projeto "Construindo a igualdade de oportunidades no mundo do trabalho: combatendo a homo-lesbo-transfobia”. Brasília: DF, 2015.

OKITA, Hiro. Homossexualidade: da opressão à libertação. 2 ed. São Paulo: Editora Sundermann, 2015.

PESSÔA, Lilian Correia. Trilhares que ensinam: incursões em experiências formativas portuguesas para ressignificação de modelos formativos brasileiros. 180f. Tese Doutorado. Pontifícia Universidade Católica de São Paulo. São Paulo. 2015.

RODRIGUES, J. Direitos humanos e diversidade sexual: uma agenda em construção. In: Fundação Perseu Abramo. Diversidade sexual e homofobia no Brasil. Editora Fundação Perseu Abramo, 2011.

SANTOS, L. N. A psicologia na assistência social: convivendo com a desigualdade. São Paulo: Cortez, 2014.

SAWAIA, B. Introdução: exclusão ou inclusão perversa? In: SAWAIA, Bader (Org.). As artimanhas da exclusão: análise psicossocial e ética da desigualdade social. Petrópolis, RJ: Vozes, 2002.

SILVA, Jorge Nascimento. A formação contínua de professores: contradiçôes de um modelo. In: MORAES, Maria Célia; PACHECO, José Augusto; EVANGELISTA, Maria Olinda. (Orgs.). Formaçáa de

Professores: perspectivas educacionais e curriculares. Porto: Porto Editora, 2003, pp. 105-125.

SOUZA, J. A Ralé Brasileira: quem é e como vive. Belo Horizonte: UFMG, 2009.

TOLEDO, R. A heteronormatividade como efeito do obscurantismo dos conservadores na construçáo dos planos de metas para a educaçáo: o silenciamento das temáticas de gênero, orientaçáo sexual e identidade de gênero. In: Anais EDUCERE XII Congresso Nacional de Educação 2015. Curitiba 2015, p. 343-356. 
WEIL, S. O enraizamento. Bauru: EDUSC, 2001.

WELLER, V. Grupos de discussão na pesquisa com adolescentes e jovens: aportes teórico-metodológicos e análise de uma experiência com o método. Disponível em: <http://www2.fct.unesp.br/docentes/geo/ necio_turra/PPGG\%20-\%20PESQUISA\%20QUALI\%20PARA\%20GEOGRAFIA/grupo\%20de $\% 20$ discuss\%E3o\%20-\%20wellwe.pdf>. Acesso em: 29 maio 2017. 